\title{
Erosion and abrasion susceptibility of enamel bleached with various bleaching agents at different frequencies
}

\author{
Karima Lubbadeh ${ }^{1}$, George J Eckert ${ }^{2}$ and Frank Lippert ${ }^{1 *}$ \\ ${ }^{1}$ Indiana University School of Dentistry, Department of Cariology, Operative Dentistry and Dental Public Health, Oral Health Research Institute, Indianapolis, \\ IN, USA \\ ${ }^{2}$ Indiana University School of Medicine, Department of Biostatistics, Indianapolis, IN, USA
}

\begin{abstract}
Purpose: To evaluate the effect of different in-office and at-home bleaching agents, applied for different periods on enamel susceptibility to erosion and brushing abrasion, in order to help dentists provide better treatment recommendations for patients that can minimize potential adverse side effects of tooth whitening treatments.

Methods: The following experimental factors were considered: three in-office bleaching treatments; (G1-Opalescence Boost 40\% hydrogen peroxide, G2-iBrite Plus 30\% hydrogen peroxide, G3-Gel White In-Office Dental Bleaching 16\% carbamide peroxide), and three at-home bleaching treatments; (G4-Opalescence PF 20\%, G5- Opalescence PF 15\%, G6- Opalescence PF 10\%); two different frequencies of applications; and two models (erosion only/erosion and abrasion). Two control groups were used; G7 for in-office and G8 for at-home bleaching treatments. Control groups specimen remained in artificial saliva during the period corresponding to bleaching procedures. Study blocks were formed by gluing two enamel slabs together, generating 80 study blocks that were distributed among 8 groups. Each group was bleached with its assigned bleaching agent, then further subdivided into two subgroups where half the slabs were subjected to another cycle of bleaching treatment. The blocks of each bleached group and corresponding control groups were then subjected to a one-day cycling model. Cycling consisted of citric acid erosive challenges and toothbrushing abrasion, where only one side of the blocks was brushed. Artificial saliva was used to remineralize the specimens after erosive and abrasive challenges, and as storage media between bleaching treatments. After each erosion/abrasion cycle, surface loss (in micrometers) was determined by noncontact profilometry. Data were analyzed using ANOVA $(\alpha=0.05)$.
\end{abstract}

Results: Bleaching did not increase enamel susceptibility to erosion or abrasion regardless of the bleaching gel concentration or frequency of application. Bleaching gels containing fluoride, calcium or potassium nitrate might have offered protection against enamel erosion and abrasion. Toothbrushing abrasion was the single most important factor contributing to tooth wear regardless of bleaching. Although it may not be of clinical significance, in-office bleaching caused more surface loss than at-home bleaching.

\section{Clinical significance}

Professional bleaching gels are not harmful to the enamel surface, especially if they contain fluoride, potassium nitrate and calcium. Patients should be advised to use low-abrasive fluoride dentifrices after bleaching. At-home bleaching gels may be favored over in-office treatments for patients already at risk of erosive tooth wear.

\section{Introduction}

Over the past twenty years tooth bleaching or whitening has become one of the most popular and relatively straightforward aesthetic treatments. The focus of dentists in this field in the early $1800 \mathrm{~s}$ was whitening of non-vital teeth that had discolored due to trauma or endodontic treatment. In the late 1980s this field had developed to introduce various bleaching techniques that were applied to vital teeth. Many products were introduced to the market for both in-office and at-home bleaching [1]. Bleaching products may be classified into three main groups; 1-high peroxide concentration products used by dental professionals for in-office tooth whitening, 2-bleaching products sold by dental professionals to be used by patients at home, 3- over-thecounter whitening products [2]. Most bleaching materials are based on either hydrogen peroxide or carbamide peroxide. Both can act as a tooth whitener, but each has different efficacy and safety considerations have been concerns over the safety of long-term unsupervised use of whitening products either due to overuse or undiagnosed underlining oral health problems. ${ }^{1,2}$ Even though tooth bleaching is generally considered a relatively safe procedure, many studies have shown various adverse effects of bleaching on both hard and soft tissues and on tooth restorations as well [3-6].

Bleaching agents release free radicals that can cause degradation of the enamel matrix. Thus, loss of tooth minerals, such as calcium and phosphorus, may occur. This can lead to a decrease in enamel microhardness, especially when high concentrations are being used, and when treatments were repeated [7-10]. It was noticed that bleaching products based on carbamide peroxide were more damaging due to longer application times [11]. Also, in-office bleaching resulted in more surface softening compared to at-home bleaching [12]. Some studies concluded that home bleaching with low peroxide concentrations did not affect enamel microhardness [13]. Using fluoride-supplemented

Correspondence to: Frank Lippert, Indiana University School of Dentistry, Department of Cariology, Operative Dentistry and Dental Public Health, Oral Health Research Institute, 415 Lansing Street, Indianapolis, IN 46202, USA. E-Mail flippert@iu.edu; Tel. +1 3172743983

Received: January 18, 2018; Accepted: February 02, 2018; Published: February 06, 2018 
bleaching products or topical fluorides immediately after bleaching decreased this adverse side effect and enhanced enamel remineralization $[11,12]$. Interestingly, the addition of amorphous calcium phosphate (ACP) or calcium to bleaching gels was not found to be successful in reversing the demineralizing effects of bleaching in both sound and carious enamel [14]. Studies have also shown morphological changes on the enamel surface after bleaching, leading to increases in enamel surface roughness and porosity and perhaps leading to more rapid discoloration in the future [7]. Nevertheless, morphological changes were not considered to be significant with home bleaching products using $10 \%$ and $15 \%$ carbamide peroxide [15]. On another hand, in situ studies suggested that there were no structural differences between bleached and unbleached teeth. That could be due to the continuous influx of fluoride and other minerals from saliva and topical oral care products to the bleached teeth that helped restore their mechanical and chemical properties the bleaching might have altered [16,17].

Because of the decreased microhardness and mineral loss, bleached enamel can become more susceptible to acid erosion. Erosion, known to be the loss of enamel surface due to exposure to acidic chemicals that are non-bacterial, became more pronounced after bleaching, especially when bleaching materials with a lower $\mathrm{pH}$ were being used $[13,18]$.

The adverse effects of bleaching on enamel can make enamel more susceptible to mechanical tooth wear (e.g. toothbrush abrasion). The abrasive surface loss increased with the use of more abrasive toothpastes and decreased when bleaching gels were supplemented with calcium and/or fluoride. Also, allowing for remineralization between bleaching and tooth brushing can minimize the potential abrasive surface loss [19]. Performing bleaching and tooth brushing together increased enamel surface roughness and decreased enamel hardness [20]. In some cases, enamel roughness was not affected after bleaching but significantly increased after brushing the bleached teeth, especially with the use of more abrasive toothpastes [21,22]. Bleaching performed with low peroxide concentrations, such as $10 \%$ carbamide peroxide, did not increase enamel surface roughness, nor did it make tooth enamel more susceptible to erosion or brushing abrasion [22,23].
As there is still considerable discrepancy in the literature about the effects of bleaching associated with erosion and tooth brushing on enamel, the present study will aim to close important gaps in our knowledge and provide clinical recommendations.

\section{Materials and methods}

\section{Study design}

This study investigated the impact of six different bleaching agents (three in-office and three at-home bleaching products) on increasing enamel surface susceptibility to erosion and brushing abrasion. The present study followed an 8 (number of groups bleached including the control groups) $\times 2$ (two different bleaching periods for each group) $\times$ 2 (erosion with and without tooth brushing abrasion) factorial design (Figure 1). Three groups were bleached with three different in-office hydrogen/carbamide peroxide bleaching agents; (G1) Opalescence Boost $40 \%$ hydrogen peroxide, (G2) iBrite Plus 30\% hydrogen peroxide, (G3) Gel White 16\% carbamide peroxide. When Gel White bleaching gel was used, the step involving etching with Gel Etch before bleaching was omitted to avoid the additional effect that the etchant might have had on the study results. Each group (10 study blocks each) was bleached with the corresponding bleaching agent for one session following manufacturer's instructions. Then each group was further divided into two more groups; G1A, G2A, G3A were bleached for one hour and stored in artificial saliva. G1B, G2B, G3B were bleached for another one-hour session with their corresponding bleaching agents. The other three groups were bleached using three different at-home carbamide peroxide bleaching agents; (G4) Opalescence 20\%, (G5) Opalescence 15\%, (G6) Opalescence 10\%. Each group was bleached following manufacturer's instructions for four different days-one hour each- and was placed in artificial saliva between bleaching cycles. Then each group was further divided into two more groups: G4A, G5A, G6A were bleached four days only and stored in artificial saliva; G4B, G5B, G6B were bleached with the corresponding bleaching agent for additional four days. Control groups (G7A and B, G8A and B) remained in artificial saliva during the time corresponding to bleaching treatments. The polished bovine enamel slabs of all groups were

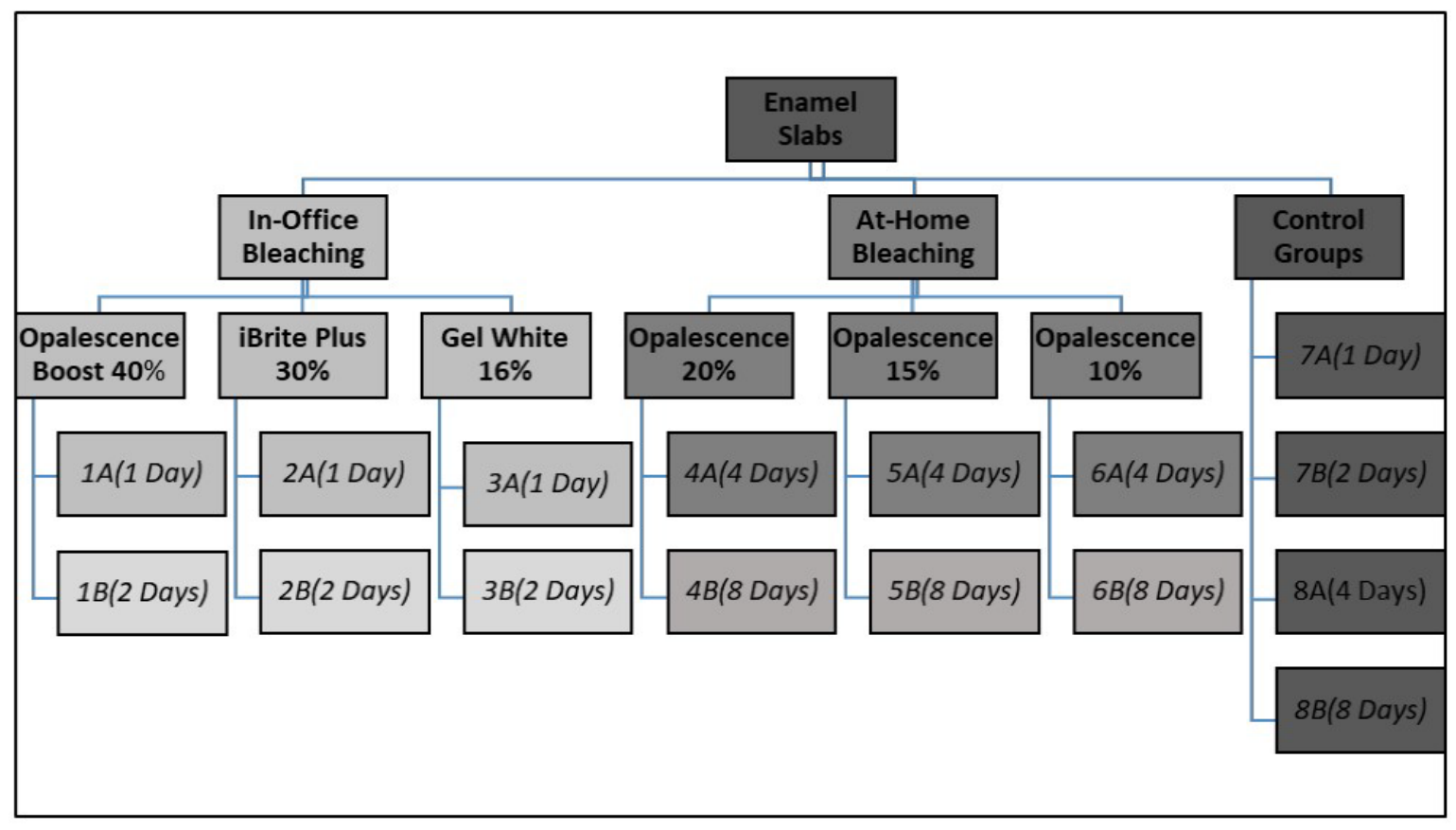

Figure 1. Illustration of the study design 
Silva FM (2018) Focusing lung transplant: physiological and antioxidant responses and effect of allopurinol to ischemia-reperfusion oxidative stress under different inspired oxygen concentrations

subjected after bleaching to a one-day erosion/abrasion cycling model carried out on four different days. Each group was exposed to two daily brushing treatments with or without abrasion and three erosive treatments. Enamel was allowed to remineralize using artificial saliva between treatments. At the end of each erosion/abrasion cycle, slabs were stored at approximately 100\% relative humidity. Then, enamel surface loss was determined using non-contact profilometry and different groups were compared (different bleaching concentrations and different bleaching periods).

\section{Study treatments}

Six different bleaching agents were chosen for this study (Table 1). Three are administered in the dental office by a dentist and three are prescribed by dentists to be used at home. All bleaching agents chosen for this study were either hydrogen peroxide or carbamide peroxide based, with different concentrations.

\section{Specimen preparation}

Enamel slabs (5 mm width $\times 5 \mathrm{~mm}$ length $\times 2 \mathrm{~mm}$ thickness) obtained from bovine incisors, stored in $0.1 \%$ thymol solution $\mathrm{pH}$ (7.0) at $4^{\circ} \mathrm{C}$, were prepared. The bottom and top of the enamel slabs were sequentially ground flat using silicon carbide grinding papers (Struers RotoPol 31/RotoForce 4 polishing unit, USA). Then, the slabs were cleaned in an ultrasonic device with deionized water for $5 \mathrm{~min}$. Then, they were embedded in acrylic resin blocks (Varidur acrylic system, Buehler, USA) utilizing custom-made silicon mold, leaving the enamel surface exposed. The embedded blocks were serially ground and polished up to 4000-grit grinding paper followed by $1 \mu \mathrm{m}$ diamond polishing suspension. Specimens were selected based on the quality of enamel. Those with crack or other defects were rejected. Two embedded specimens were glued together to form the study block. The blocks remained together throughout the study. During exposure to toothpaste treatment, the entire block was submerged in the toothpaste slurry with one side only being exposed to toothbrush abrasion. The study blocks were randomly assigned to eight enamel groups with ten specimen blocks per group $(\mathrm{n}=10)$.

\section{Surface area delimitation}

Adhesive UPVC (unplasticized polyvinyl chloride) tapes were placed on the surface of the specimens, leaving an area of $1 \times 5 \mathrm{~mm}$ exposed in the center of each of the enamel slab.

\section{Treatment regimen}

Each study group was bleached with its corresponding bleaching regimen following the manufacturer's instructions. Half of the slabs were bleached double the time. After each group completed its designated bleaching protocol, the specimens were then subjected to the erosion/abrasion regimen for one day (see below). Then slabs were stored at approximately $100 \%$ relative humidity in closed containers until profilometry was performed (Table 2).

Table 1. Bleaching agents and assigned groups

\begin{tabular}{|c|c|c|c|c|c|}
\hline Group Numbers & Product Name & Product Type & Whitening Agent & Peroxide Concentration & Other Active Ingredients \\
\hline G1A, G1B & $\begin{array}{l}\text { Opalescence Boost } \\
\text { (Ultradent,USA) }\end{array}$ & In-office & Hydrogen peroxide & $40 \%$ & Potassium nitrate, fluoride \\
\hline $\mathrm{G} 2 \mathrm{~A}, \mathrm{G} 2 \mathrm{~B}$ & $\begin{array}{l}\text { iBrite Plus } \\
\text { (Pac-Dent International,USA) }\end{array}$ & In-office & Hydrogen peroxide & $30 \%$ & $\begin{array}{l}\text { Potassium nitrate, fluoride, } \\
\text { calcium }\end{array}$ \\
\hline G3A, G3B & $\begin{array}{l}\text { Gel White } \\
\text { (Temrex, USA) }\end{array}$ & In-office & Carbamide peroxide & $16 \%$ & None \\
\hline G4A, G4B & $\begin{array}{l}\text { Opalescence } \\
\text { (Ultradent,USA) }\end{array}$ & At-home & Carbamide peroxide & $20 \%$ & Potassium nitrate, fluoride \\
\hline G5A, G5B & $\begin{array}{l}\text { Opalescence } \\
\text { (Ultradent,USA) }\end{array}$ & At-home & Carbamide peroxide & $15 \%$ & Potassium nitrate, fluoride \\
\hline G6A, G6B & $\begin{array}{l}\text { Opalescence } \\
\text { (Ultradent,USA) }\end{array}$ & At-home & Carbamide peroxide & $10 \%$ & Potassium nitrate, fluoride \\
\hline
\end{tabular}

Table 2. Treatment Protocol

\begin{tabular}{|c|c|c|}
\hline & Treatment & Storage Media \\
\hline Day1 & $\begin{array}{l}\text { Bleaching G1 }(A+B), G 2(A+B), G 3(A+B), G 4(A+B), G 5(A+B), G 6(A+B) \text { for } 60 \mathrm{~min} \\
\text { G7 }(A+B), G 8(A+B) \text { in Artificial Saliva for } 60 \mathrm{~min}\end{array}$ & Artificial Saliva for all groups \\
\hline Day2 & $\begin{array}{l}\text { Bleaching G4(A+B), G5(A+B), G6(A+B) for } 60 \mathrm{~min} \\
\text { Ero/Abr G1A, G2A, G3A, G7A } \\
\text { Storing G1B, G2B, G3B, G7B } \\
\text { G8(A+B) in Artificial Saliva for } 60 \mathrm{~min}\end{array}$ & $\begin{array}{l}\text { Artificial Saliva } \\
100 \% \text { Humidity } \\
100 \% \text { Humidity } \\
\text { Artificial Saliva }\end{array}$ \\
\hline Day3 & $\begin{array}{l}\text { Bleaching G1B, G2B, G3B, G4(A+B), G5(A+B), G6(A+B) for } 60 \mathrm{~min} \\
\text { G7B, G8(A+B) in Artificial Saliva for } 60 \mathrm{~min}\end{array}$ & $\begin{array}{l}\text { Artificial Saliva } \\
\text { Artificial Saliva }\end{array}$ \\
\hline Day4 & $\begin{array}{l}\text { Bleaching } \mathrm{G} 4(\mathrm{~A}+\mathrm{B}), \mathrm{G} 5(\mathrm{~A}+\mathrm{B}), \mathrm{G} 6(\mathrm{~A}+\mathrm{B}) \text { for } 60 \mathrm{~min} \\
\text { Ero/Abr G1B, G2B, G3B, G7B } \\
\text { G8(A+B) in Artificial Saliva for } 60 \mathrm{~min}\end{array}$ & $\begin{array}{l}\text { Artificial Saliva } \\
100 \% \text { Humidity } \\
\text { Artificial Saliva }\end{array}$ \\
\hline Day5 & $\begin{array}{l}\text { Ero/Abr G4A, G5A, G6A, G8A } \\
\text { Storing G4B, G5B, G6B, G8B }\end{array}$ & $\begin{array}{l}100 \% \text { Humidity } \\
100 \% \text { Humidity }\end{array}$ \\
\hline Day6 & $\begin{array}{l}\text { Bleaching G4B, G5B, G6B for } 60 \mathrm{~min} \\
\text { G8B in Artificial Saliva for } 60 \mathrm{~min}\end{array}$ & $\begin{array}{l}\text { Artificial Saliva } \\
\text { Artificial Saliva }\end{array}$ \\
\hline Day7 & $\begin{array}{l}\text { Bleaching G4B, G5B, G6B for } 60 \mathrm{~min} \\
\text { G8B in Artificial Saliva for } 60 \mathrm{~min}\end{array}$ & $\begin{array}{l}\text { Artificial Saliva } \\
\text { Artificial Saliva }\end{array}$ \\
\hline Day8 & $\begin{array}{l}\text { Bleaching G4B, G5B, G6B for } 60 \mathrm{~min} \\
\text { G8B in Artificial Saliva for } 60 \mathrm{~min}\end{array}$ & $\begin{array}{l}\text { Artificial Saliva } \\
\text { Artificial Saliva }\end{array}$ \\
\hline Day9 & $\begin{array}{l}\text { Bleaching G4B, G5B, G6B for } 60 \mathrm{~min} \\
\text { G8B in Artificial Saliva for } 60 \mathrm{~min}\end{array}$ & $\begin{array}{l}\text { Artificial Saliva } \\
\text { Artificial Saliva }\end{array}$ \\
\hline Day10 & Ero/Abr G4B, G5B, G6B, G8B & $100 \%$ Humidity \\
\hline
\end{tabular}


Silva FM (2018) Focusing lung transplant: physiological and antioxidant responses and effect of allopurinol to ischemia-reperfusion oxidative stress under different inspired oxygen concentrations

\section{Bleaching treatments}

Study groups were bleached as shown in (Table 3). After each bleaching treatment, the gel was removed with a cotton swab and the surface rinsed with deionized water. At the end of each bleaching cycle slabs were stored in artificial saliva until all bleaching was completed and erosion/abrasion cycle was performed.

\section{Erosion/Abrasion cycle}

The daily cycling procedure is show in (Table 4 ). After the assigned bleaching regimen for each group was completed, slabs were subjected to two brushing cycles with Crest Cavity Protection (Procter \& Gamble, Cincinnati, OH, USA) regular toothpaste as an aqueous slurry (one part toothpaste to three parts deionized water) with one side only of the slabs being brushed, and three 5 minutes erosive treatments with citric acid solution. Slabs were allowed to remineralize in artificial saliva for one hour between treatments.

\section{Brushing abrasion}

Specimens were positioned in an automated brushing machine. They were brushed two times daily for 45 stokes/15 s each (automated V-8 brushing machine) with Oral B 40 toothbrushes (Procter \& Gamble, Cincinnati, OH, USA) using a Crest Cavity Protection toothpaste slurry.

\section{Erosive solution}

The demineralization solution was composed of $0.3 \%$ citric acid anhydrous in deionized water ( $\mathrm{pH} 2.6$, adjusted, if needed, with $1 \mathrm{~N}$ $\mathrm{NaOH}$ or HCl; Sigma-Aldrich, St. Louis, MO, USA).

Table 3. Bleaching Treatment Regimen

\begin{tabular}{|c|c|c|c|}
\hline Group Number & Bleaching Agent & Bleaching Time & $\begin{array}{c}\text { Number of Days } \\
\text { Bleached }\end{array}$ \\
\hline G1A & Opalescence Boost 40\% & $60 \mathrm{~min}$ & 1 \\
\hline G2A & iBrite Plus 30\% & $60 \mathrm{~min}$ & 1 \\
\hline G3A & Gel White $16 \%$ & $60 \mathrm{~min}$ & 1 \\
\hline G1B & Opalescence Boost $40 \%$ & $60 \mathrm{~min}$ & 2 \\
\hline G2B & iBrite Plus $30 \%$ & $60 \mathrm{~min}$ & 2 \\
\hline G3B & Gel White $16 \%$ & $60 \mathrm{~min}$ & 2 \\
\hline G4A & Opalescence $20 \%$ & $60 \mathrm{~min}$ & 4 \\
\hline G5A & Opalescence $15 \%$ & $60 \mathrm{~min}$ & 4 \\
\hline G6A & Opalescence $10 \%$ & $60 \mathrm{~min}$ & 4 \\
\hline G4B & Opalescence $20 \%$ & $60 \mathrm{~min}$ & 8 \\
\hline G5B & Opalescence $15 \%$ & $60 \mathrm{~min}$ & 8 \\
\hline G6B & Opalescence $10 \%$ & $60 \mathrm{~min}$ & 8 \\
\hline
\end{tabular}

Table 4. Erosion/Abrasion cycling regimen

\begin{tabular}{|l|l|l|}
\hline \multicolumn{2}{|l|}{ Treatment } & Duration \\
\hline Step 1 & $\begin{array}{l}\text { Exposure to toothpaste slurry in brushing machine (one side } \\
\text { brushed [abrasion] and one side not brushed) (1 of 2) }\end{array}$ & $\begin{array}{l}15 \mathrm{~s} \\
\text { (45 strokes) }\end{array}$ \\
\hline Step 2 & Remineralization in artificial saliva (1 of 5) & $60 \mathrm{~min}$ \\
\hline Step 3 & Erosion with citric acid (1 of 3) & $5 \mathrm{~min}$ \\
\hline Step 4 & Remineralization in artificial saliva (2 of 5) & $60 \mathrm{~min}$ \\
\hline Step 5 & Erosion with citric acid (2 of 3) & $5 \mathrm{~min}$ \\
\hline Step 6 & Remineralization in artificial saliva (3 of 5) & $60 \mathrm{~min}$ \\
\hline Step 7 & Erosion with citric acid (3 of 3) & $5 \mathrm{~min}$ \\
\hline Step 8 & Remineralization in artificial saliva (4 of 5) & $60 \mathrm{~min}$ \\
\hline Step 9 & $\begin{array}{l}\text { Exposure to toothpaste slurry in brushing machine (one side } \\
\text { brushed [abrasion] and one side not brushed) (2 of 2) }\end{array}$ & $15 \mathrm{~s} \mathrm{(45} \mathrm{strokes)}$ \\
\hline Step 10 & Remineralization in artificial saliva (5 of 5) & $60 \mathrm{~min}$ \\
\hline
\end{tabular}

\section{Remineralization media}

Artificial saliva with the following composition was used as remineralization medium: $1.45 \mathrm{mM} \mathrm{CaCl}_{2}, 5.4 \mathrm{mM} \mathrm{KH}_{2} \mathrm{PO}_{4}, 0.1 \mathrm{M}$ Tris buffer, $2.2 \mathrm{~g} / \mathrm{L}$ porcine gastric mucin (adjusted to $\mathrm{pH} 7.0$ with $\mathrm{KOH}$; Sigma Aldrich, St. Louis, MO, USA). ${ }^{24}$

\section{Profilometry}

After completion of the study, surface loss (SL) was measured using an optical profilometer (Proscan 2000, Scantron, United Kingdom). The tapes were removed from the specimens, and then they were positioned in the optical profilometer having the experimental surface parallel to the horizontal plan. An area of $2 \times 1 \mathrm{~mm}^{2}$ covering both the two references and treated surfaces were scanned, using horizontal resolutions of 0.01 and $0.1 \mu \mathrm{m}$, in the $x$ and $y$ directions, respectively. Images were analyzed using dedicated software (Proscan 2000; Scantron, United Kingdom), which calculated the average height of the two reference areas and subtracted it from the experimental area. The difference in the depth (surface loss), expressed in $\mu \mathrm{m}$, was the response variable of the present study.

\section{Statistical methods}

The effects of bleaching treatments, repeated bleaching, and brushing on surface loss were analyzed using ANOVA. The ANOVA included fixed effects for the three factors as well as their interactions and a random effect to account for correlation between the brushed and non-brushed samples. Pair-wise comparisons were made using Fisher's Protected Least Significant Differences to control the overall significance level. A 5\% significance level was used for all tests.

\section{Results}

The two-way and three-way interactions among the factors were not significant (Table 5). Brushing had significantly more surface loss than no brushing $(p<0.0001$; Figures 2 and 3$)$. Repeated bleaching did not have a significant effect on surface loss $(\mathrm{p}=0.46$; Figures 2 and 3$)$.

Significant differences were found among treatments $(\mathrm{p}=0.0215)$ : Control for in-office had more surface loss than in-office treatment iBrite Plus ( $\mathrm{p}=0.0155)$ (Figure 2). Control for at-home had more surface loss than at-home treatments Opalescence 20\% $(\mathrm{p}=0.0491)$ and Opalescence 10\% ( $\mathrm{p}=0.0314)$ (Figure 3).

In-office treatments had more surface loss than at-home treatments ( $\mathrm{p}=0.0436$; Figure 4).

\section{Discussion}

There were contradictory results among studies assessing the harmful effects of bleaching gels, which necessitated further investigation. Many variables had to be taken into consideration to reconcile gaps. The present study was novel as it addressed the effect of in-office and at-home bleaching products, their frequency of use, combined with erosion and abrasion in a comprehensive manner. The current study demonstrated that bleaching, regardless of the bleaching treatment concentration, did not increase enamel surface loss with erosion or erosion/abrasion challenges. Other studies showed similar results, concluding that surface loss occurred with erosion or tooth brushing abrasion and not with bleaching. Bleaching treatments, especially home bleaching with low carbamide peroxide concentrations did not have deleterious effects [17,23]. Similarly, other studies concluded that bleaching gels did not alter calcium and phosphate content of dental enamel and therefore did not cause demineralization, 
Silva FM (2018) Focusing lung transplant: physiological and antioxidant responses and effect of allopurinol to ischemia-reperfusion oxidative stress under different inspired oxygen concentrations

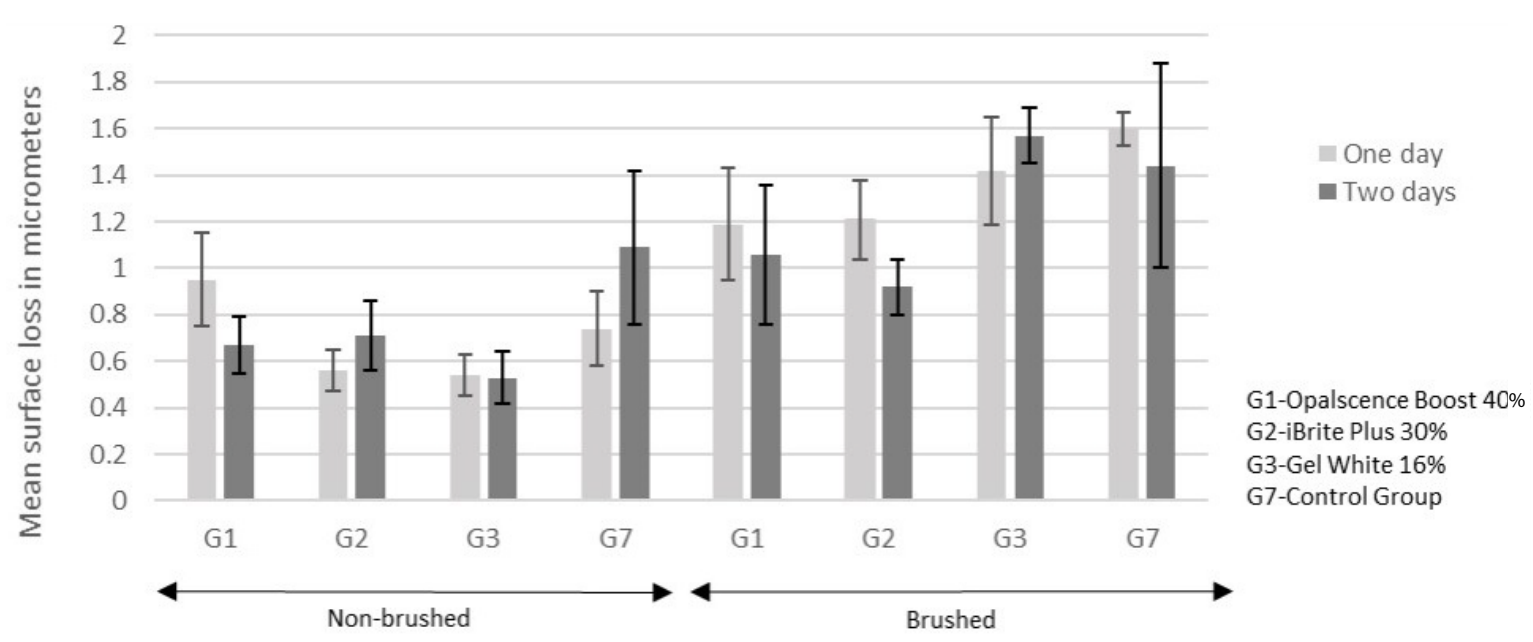

Bleaching Treatments

Figure 2. Mean \pm standard error of the surface loss for in-office treatments

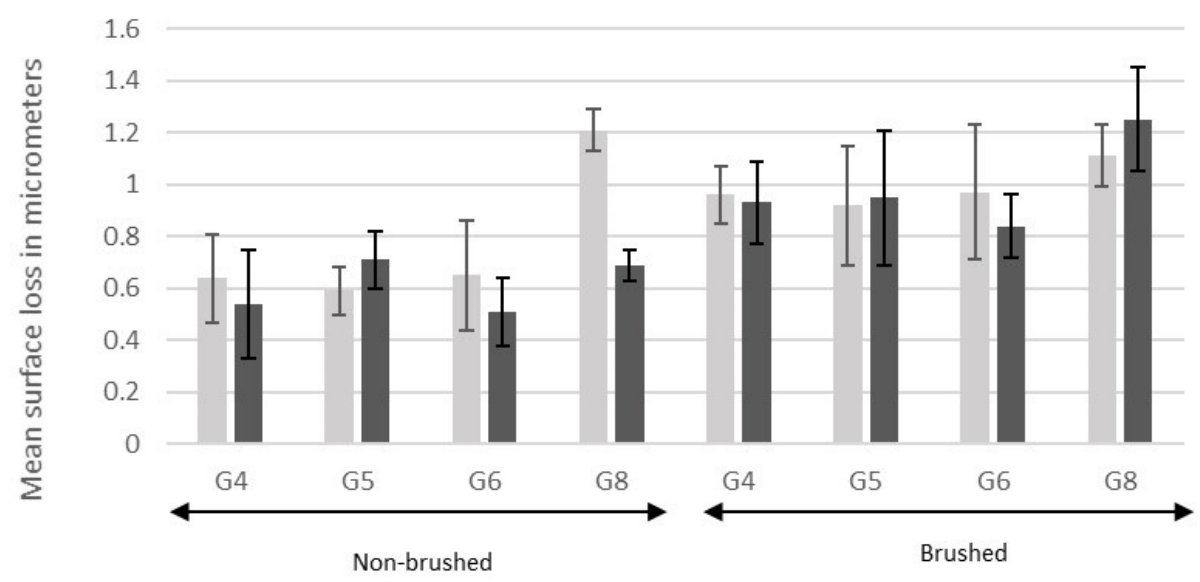

$$
\begin{aligned}
& 4 \text { Days } \\
& \text { - } 8 \text { Days }
\end{aligned}
$$

Bleaching Treatments

Figure 3. Mean \pm standard error of the surface loss for at-home treatments

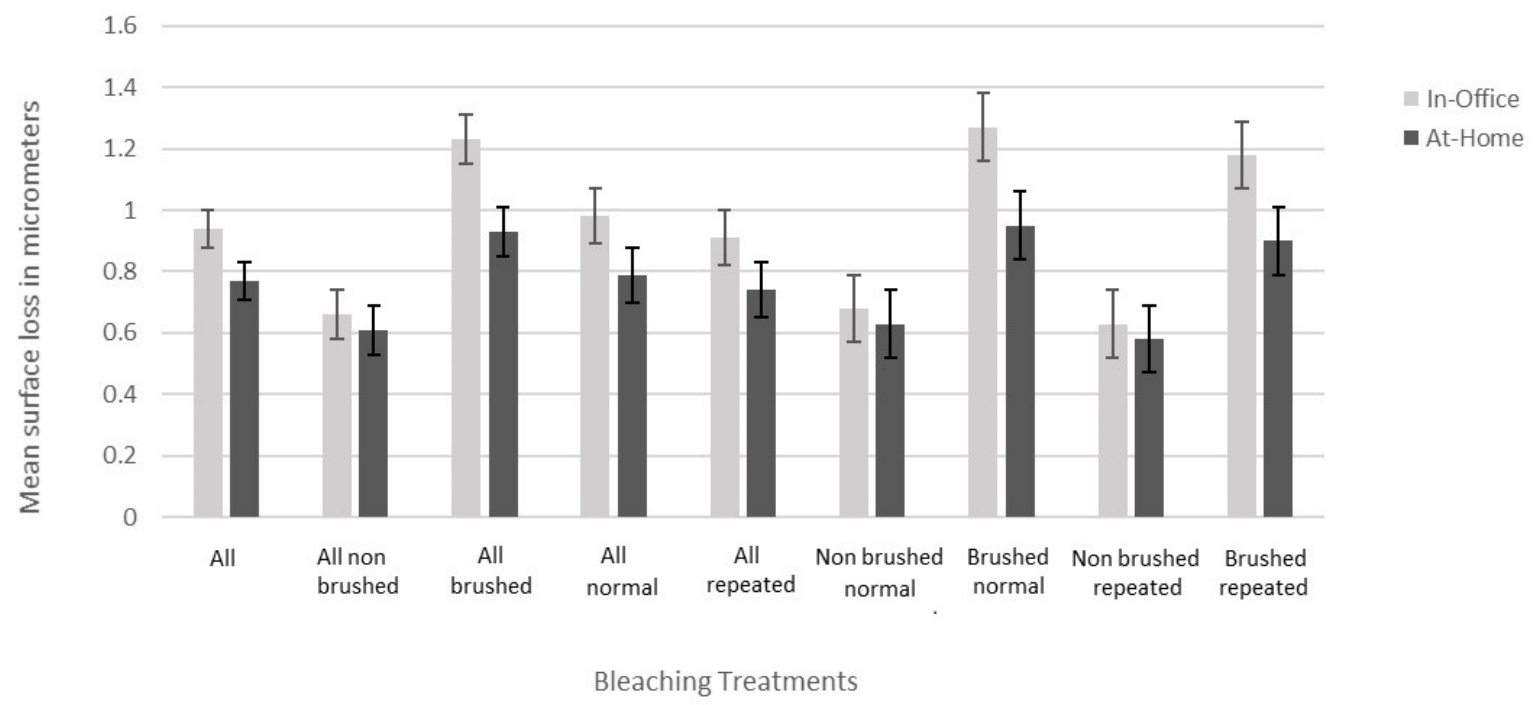

Figure 4. Mean \pm standard error of the surface loss for combined in-office and at-home treatments 
no matter how excessively they were used [25]. Also studies that analyzed surface roughness showed no statistically significant difference between bleached and unbleached enamel when using home bleaching agents [15]. On the other hand, some studies proved that even though bleaching did not alter surface roughness, it increased surface wear when combined with brushing. Brushed bleached enamel showed more surface roughness and wear when compared to unbleached enamel [21]. This deleterious effect of bleaching combined with brushing increased with the use of the more abrasive whitening dentifrice and may not be statistically significant with the use of fluoridated toothpastes, such as the one used in the current study [20]. Studies that experimented with excessive multiple session bleaching with $35 \%$ hydrogen peroxide showed decrease in calcium ion percentages leading to morphological changes in enamel surface [9]. In the present study, bleaching was performed in a way similar to how it would normally be applied in a patient's mouth and excessive bleaching was avoided. Also, some studies have shown that using bleaching gels with concentrations such as $10 \%$ and $16 \%$ carbamide peroxide for long durations resulted in decreasing enamel microhardness, decrease in calcium and phosphate content and increase in surface roughness $[7,11]$. Similarly it was found that bleaching increased enamel demineralization [14]. Also, studies found an increase in enamel susceptibility to acid erosion and mineral loss after bleaching [18]. It is important to remember though that these studies were conducted in vitro where the remineralizing effect of saliva is often absent. In situ studies showed no significant differences between bleached and unbleached enamel whether mechanical, chemical or morphological properties are being considered $[16,17]$. In these studies, bleaching was performed intra-orally with continuous exposure to saliva [26]. In the present study, overnight remineralization was performed in artificial saliva after each bleaching cycle and $60 \mathrm{~min}$ of remineralization was allowed between treatment challenges during cycling, to mimic salivary remineralization that would take place in the oral cavity.

Repeated bleaching and bleaching treatment concentrations did not have a significant effect on surface loss. Other studies proved otherwise, showing that higher bleaching gel concentrations lead to more intense adverse effects on enamel, more softening, mineral loss and increased roughness [3,7]. Similarly, studies showed more adverse effects and morphologic changes with longer periods of bleaching application $[3,7,9,18]$. It is important to point out that different experimental parameters can potentially lead to varying outcomes. Most studies used different methodologies and there were considerable variations in the composition of enamel samples, types of bleaching gels used, the bleaching conditions, duration of applications, the kind of erosive/abrasive challenges and techniques used to quantify surface loss. Therefore, it is not surprising to encounter contradictory results [26]

Interestingly, in-office treatments caused more surface loss than at-home treatments $(\mathrm{p}=0.0436)$. This difference was consistent with erosive and abrasive challenges and whether bleaching periods were repeated or not (Figure 4). Similar results were shown in a study investigating changes in enamel surface microhardness [12]. The safety of at-home bleaching gels was also demonstrated by showing that their use in different concentrations and different time periods did not cause any statistically significant changes in surface roughness and morphology [15]. This may be due to various factors, such as chemical composition, method, and mechanism of application. There was no effect of bleaching gel peroxide concentration between in-office or athome bleaching products, which warrants further, more longitudinal studies. Although a potential difference may not be of any clinical significance, since bleaching did not have a harmful effect overall, it may serve as a guideline when choosing the bleaching treatment for patients with certain risk factors, such as pre-existing erosive-abrasive lesions, patients having more acidic diet, patients with tooth grinding habits or more sensitive teeth.

This study also confirmed the harmful effects of abrasion when combined with erosion and regardless of bleaching. $(p<0.0001)$ This result is supported by studies concluding that bleaching played no role in increasing enamel surface wear $[22,23,27]$. The extent of surface loss depends on the abrasiveness of a dentifrice used and the amount of time allowed for remineralization between bleaching and brushing. It was found that giving at least an hour after bleaching contributed to strengthening and re-hardening the enamel weakened by the process of bleaching [19]. In the present study, brushing was performed the following day after overnight remineralization with artificial saliva. This might have allowed for sufficient remineralization to occur after bleaching and therefore bleached samples did not show greater surface loss with brushing or acid erosion compared to unbleached samples. Brushed samples, however, showed more surface loss whether bleached or not. Some studies showed some increase in toothbrushing abrasion after bleaching, although only when associated with certain bleaching treatments with these increases being clinically questionable [27].

Interestingly, in the present study some control (unbleached) groups showed more surface loss after cycling compared to the bleached groups. This may be due to the presence of protective minerals that were being added to the bleaching gels to promote remineralization and strengthening of enamel surface against erosion and abrasion. All bleaching gels used in this study, except Gel White In-Office bleaching, contained added minerals such as fluoride, potassium nitrate and/or calcium. The type and concentration of minerals being added differs among different bleaching agents and thus this protective effect likely differs between gels. Certain mineral combinations and interactions between different gels' contents may make some gels more protective and safer to use than others. This may be a topic for future studies, trying to identify the most efficient mineral combination and concentration thereof to further minimize potentially harmful effects of bleaching while enhancing post-bleaching recovery of enamel. On the contrary, some studies concluded that adding calcium ions or ACP to bleaching gels did not promote remineralization whether in sound or carious enamel. It did not protect sound enamel from demineralization or promote remineralization of early carious lesions [14]. However, several studies proved otherwise. They showed that the addition of fluoride and calcium to bleaching gels could reduce mineral loss associated with bleaching [28-30]. Fluoridated bleaching gels caused less demineralization and less reduction in enamel microhardness [29-31]. Similarly, it was found that fluoridation after bleaching can completely restore softened enamel, such as using fluoridated mouth rinses following bleaching protocols [12]. The active role of remineralization was also proven by the results obtained from in-situ studies showing that bleaching did not produce any morphological, chemical or mechanical changes in enamel due to the continuous influx of fluoride and other minerals through saliva [16] The protective role remineralizing agents play in strengthening enamel was also demonstrated in studies that proved that adding calcium to bleaching gels was capable of remineralizing early white spot lesions, resulting in higher enamel surface microhardness after bleaching [29]. Similarly, adding calcium to bleaching gels resulted in less surface loss after abrasion [19].

\section{Conclusion}

Tooth bleaching, regardless of the bleaching agent concentration and frequency of application, did not increase enamel surface 
Silva FM (2018) Focusing lung transplant: physiological and antioxidant responses and effect of allopurinol to ischemia-reperfusion oxidative stress under different inspired oxygen concentrations

susceptibility to erosion and abrasion. Agents such as fluoride, potassium nitrate and calcium, when added to bleaching gels, offered protection to enamel surface against erosion and abrasion. Brushing played a major role in surface loss, regardless of bleaching, and therefore brushing with a less abrasive fluoridated dentifrice should be recommended after bleaching. In-office bleaching caused more surface loss than at-home bleaching, which may not be of clinical significance, but can be used as a guideline when bleaching is prescribed to patients with increased risk to erosive and/or abrasive surface loss.

\section{Disclosure statement}

The present study was solely funded by the Oral Health Research Institute Remineralization Research Program. The authors declare no conflict of interest.

\section{References}

1. ADA Council on Scientific Affairs. Tooth Whitening/Bleaching: Treatment Considerations for Dentists and Their Patients. September 2009.

2. Li Y (1996) Biological properties of peroxide-containing tooth whiteners. Food Chem Toxicol 34: 887-904. [Crossref]

3. Goldberg M, Grootveld M, Lynch E (2010) Undesirable and adverse effects of toothwhitening products: a review. Clin Oral Investig 14: 1-10. [Crossref]

4. Attin T, Hannig C, Wiegand A, Attin R (2004) Effect of bleaching on restorative materials and restorations--a systematic review. Dent Mater 20: 852-861. [Crossref]

5. Dahl JE, Pallesen U (2003) Tooth bleaching--a critical review of the biological aspects. Crit Rev Oral Biol Med 14: 292-304. [Crossref]

6. Minoux M, Serfaty R (2008) Vital tooth bleaching: biologic adverse effects-a review. Quintessence Int 39: 645-659. [Crossref]

7. Soares DG, Ribeiro AP, Sacono NT, Loguercio AD, Hebling J, et al. (2013) Minera loss and morphological changes in dental enamel induced by a $16 \%$ carbamide peroxide bleaching gel. Braz Dent $J$ 24: 517-521. [Crossref]

8. Elfallah HM, Swain MV (2013) A review of the effect of vital teeth bleaching on the mechanical properties of tooth enamel. $N Z$ Dent $J$ 109: 87-96. [Crossref]

9. Souza RO, Lombardo GH, Pereira SM, et al. (2010) Analysis of tooth enamel after excessive bleaching: a study using scanning electron microscopy and energy dispersive $\mathrm{x}$-ray spectroscopy. Int J Prosthodont 23: 29-32. [Crossref]

10. Soldani P, Amaral CM, Rodrigues JA (2010) Microhardness evaluation of in situ vital bleaching and thickening agents on human dental enamel. Int $J$ Periodontics Restorative Dent 30: 203-211. [Crossref]

11. Grobler SR, Majeed A, Moola MH (2009) Effect of various tooth-whitening products on enamel microhardness. SADJ 64: 474-479. [Crossref]

12. Lewinstein I, Fuhrer N, Churaru N, Cardash H (2004) Effect of different peroxide bleaching regimens and subsequent fluoridation on the hardness of human enamel and dentin. J Prosthet Dent 92: 337-342. [Crossref]

13. Lopes GC, Bonissoni L, Baratieri LN, Vieira LC, Monteiro S, Jr. (2002) Effect of bleaching agents on the hardness and morphology of enamel. $J$ Esthet Restor Dent 14: $24-30$.

14. Berger SB, Pavan S, Dos Santos PH, Giannini M, Bedran-Russo AK (2012) Effect of bleaching on sound enamel and with early artificial caries lesions using confocal laser microscopy. Braz Dent J 23: 110-115. [Crossref]
15. Cobankara FK, Unlü N, Altinöz HC, Füsun O (2004) Effect of home bleaching agents on the roughness and surface morphology of human enamel and dentine. Int Dent J 54 211-218. [Crossref]

16. Smidt A, Feuerstein O, Topel M (2011) Mechanical, morphologic, and chemical effects of carbamide peroxide bleaching agents on human enamel in situ. Quintessence Int 42 : 407-412. [Crossref]

17. Faraoni-Romano JJ, Turssi CP, Serra MC (2009) Effect of a 10\% carbamide peroxide on wear resistance of enamel and dentine: in situ study. J Dent 37: 273-278. [Crossref]

18. Zanet CG, Fava M, Alves LA (2011) In vitro evaluation of the microhardness of bovine enamel exposed to acid solutions after bleaching. Braz Oral Res 25: 562-567. [Crossref]

19. Borges AB, Santos LF, Augusto MG, Bonfiette D, Hara AT, et al. (2016) Toothbrushing abrasion susceptibility of enamel and dentin bleached with calcium-supplemented hydrogen peroxide gel. J Dent 49: 54-59.

20. Bolay S, Cakir FY, Gurgan S (2012) Effects of toothbrushing with fluoride abrasive and whitening dentifrices on both unbleached and bleached human enamel surface in terms of roughness and hardness: an in vitro study. J Contemp Dent Pract 13: 584-589. [Crossref]

21. Mondelli RF, Azevedo JF, Francisconi PA, Ishikiriama SK, Mondelli J (2009) Wear and surface roughness of bovine enamel submitted to bleaching. Eur J Esthet Dent 4 396-403. [Crossref]

22. Worschech CC, Rodrigues JA, Martins LR, Ambrosano GM (2006) Brushing effect of abrasive dentifrices during at-home bleaching with $10 \%$ carbamide peroxide on enamel surface roughness. J Contemp Dent Pract 7: 25-34. [Crossref]

23. Engle K, Hara AT, Matis B, Eckert GJ, Zero DT (2010) Erosion and abrasion of enamel and dentin associated with at-home bleaching: an in vitro study. $J$ Am Dent Assoc 141 : 546-551. [Crossref]

24. Firatli E, Unal T, Onan U, Sandalli P (1994) Antioxidative activities of some chemotherapeutics. A possible mechanism in reducing gingival inflammation. $J$ Clin Periodontol 21: 680-683.

25. Moreira RF, Santos FP1, Santos EA1, Dos Santos RS2, Dos Anjos MJ2, et al. (2017) Analysis of the Chemical Modification of Dental Enamel Submitted to 35\% Hydrogen Peroxide "In-Office" Whitening, with or without Calcium. Int J Dent 2017: 4646789. [Crossref]

26. Spalding M, Taveira LA, de Assis GF (2003) Scanning electron microscopy study of dental enamel surface exposed to $35 \%$ hydrogen peroxide: alone, with saliva, and with 10\% carbamide peroxide. J Esthet Restor Dent 15: 154-164; discussion 165. [Crossref]

27. Wiegand A, Otto YA, Attin T (2004) In vitro evaluation of toothbrushing abrasion of differently bleached bovine enamel. Am J Dent 17: 412-416. [Crossref]

28. Cavalli V, Rodrigues LK, Paes-Leme AF, et al. (2011) Effects of the addition of fluoride and calcium to low-concentrated carbamide peroxide agents on the enamel surface and subsurface. Photomed Laser Surg 29: 319-325. [Crossref]

29. Borges AB, Guimaraes CA, Bresciani E, Ramos CJ, Borges AL, et al. (2014) Effect of incorporation of remineralizing agents into bleaching gels on the microhardness of bovine enamel in situ. J Contemp Dent Pract 15: 195-201. [Crossref]

30. Borges AB, Samezima LY, Fonseca LP, Yui KC, Borges AL, et al. (2009) Influence of potentially remineralizing agents on bleached enamel microhardness. Oper Dent 34: 593-597. [Crossref]

31. Chen H-P, Chang C-H, Liu J-K, Chuang S-F, Yang J-Y (2008) Effect of fluoride containing bleaching agents on enamel surface properties. $J$ Dent 36 : 718-725. [Crossref]

Copyright: (C2018 Silva FM. This is an open-access article distributed under the terms of the Creative Commons Attribution License, which permits unrestricted use, distribution, and reproduction in any medium, provided the original author and source are credited. 